\title{
Pancreatic cancer associated with obesity and diabetes: an alternative approach for its targeting
}

\author{
Ramesh Pothuraju1', Satyanarayana Rachagani', Wade M. Junker ${ }^{1,2}$, Sanjib Chaudhary ${ }^{1}$, Viswanathan Saraswathi',
} Sukhwinder Kaur ${ }^{1}$ and Surinder K. Batra ${ }^{1,4,5^{*}}$

\begin{abstract}
Background: Pancreatic cancer (PC) is among foremost causes of cancer related deaths worldwide due to generic symptoms, lack of effective screening strategies and resistance to chemo- and radiotherapies. The risk factors associated with PC include several metabolic disorders such as obesity, insulin resistance and type 2 diabetes mellitus (T2DM). Studies have shown that obesity and T2DM are associated with PC pathogenesis; however, their role in PC initiation and development remains obscure.

Main body: Several biochemical and physiological factors associated with obesity and/or T2DM including adipokines, inflammatory mediators, and altered microbiome are involved in PC progression and metastasis albeit by different molecular mechanisms. Deep understanding of these factors and causal relationship between factors and altered signaling pathways will facilitate deconvolution of disease complexity as well as lead to development of novel therapies. In the present review, we focuses on the interplay between adipocytokines, gut microbiota, adrenomedullin, hyaluronan, vanin and matrix metalloproteinase affected by metabolic alteration and pancreatic tumor progression.

Conclusions: Metabolic diseases, such as obesity and T2DM, contribute PC development through altered metabolic pathways. Delineating key players in oncogenic development in pancreas due to metabolic disorder could be a beneficial strategy to combat cancers associated with metabolic diseases in particular, PC.
\end{abstract}

Keywords: Pancreatic cancer, Obesity, Insulin resistance, Diabetes, Adiponectin, Leptin, Gut microbiota, Inflammation

\section{Background}

The pancreas contains exocrine and endocrine cells. The endocrine cells secrete insulin, glucagon, and somatostatin, whereas exocrine cells are involved in the secretion of digestive enzymes. Pancreatic cancer (PC) is lethal malignancy and approximately, $95 \%$ of $\mathrm{PC}$ has an exocrine cell origin. It is very difficult to diagnose at an early stage due to the lack of symptoms and deep retroperitoneal of pancreas. This PC type is commonly known as pancreatic ductal adenocarcinoma (PDAC), with a 5 -year survival rate of $\sim 7.2 \%$ in the United States

\footnotetext{
*Correspondence: sbatra@unmc.edu

'Department of Biochemistry and Molecular Biology, University of Nebraska Medical Center, Omaha, NE, USA

${ }^{4}$ Fred \& Pamela Buffet Cancer Center, University of Nebraska Medical Center, Omaha, NE, USA

Full list of author information is available at the end of the article
}

(US) [1]. PC has become the third leading cause of cancer-related deaths with an estimated new cases of 55,440 and deaths of 44,330 in 2018 [2]. The lifetime risk of developing PC in any one person is $1.6 \%$ and it is expected to surpass colon cancer in mortality by year 2030 [3]. PC is frequently diagnosed at an advanced stage, when the cancer has metastasized to distant organs like the liver, lung, lymph node and peritoneal cavity [4]. Unfortunately by the clinical presentation, $85 \%$ of the tumors are unresectable $[5,6]$ which translates to poor prognosis and high mortality in the absence of effective chemo- and radiotherapies. Risk factors for PDAC include age (high percentage in elderly), sex (high incidence in men), gene mutations, cigarette smoking (nearly one quarter of all PC cases), obesity, chronic pancreatitis, and diabetes $[7,8]$. 
In $\mathrm{PC}$, pancreatic stellate cells form a dense stromal tissue, which is referred to as a desmoplastic reaction. Stellate cells are responsible for limiting vascularization, which leads to hypoxia, tumor progression, invasion, and metastasis [9-13]. In PC, a compendium of mutations occur in various oncogenes like Kirsten rat sarcoma viral oncogene homolog (KRAS) and tumor suppressor genes (INK4A/p16, Tp53 and SMAD4) [14]. Mutations in the KRAS oncogene, observed in more than $90 \%$ of PC tumors, leads to constitutively active Ras protein that results in uncontrolled cell proliferation. Further, inactivating mutations in INK4A/p16 and Tp53 results in the loss of cell cycle and apoptotic regulation [4]. Differential expression of epidermal growth factor receptor (EGFR), mucins (MUC1, MUC6 and MUC5AC) and matrix metalloproteinases (MMPs) occurs during precursor development [15]. Mutations in INK4A/p16 (90\%) appear in PanIN-2, whereas Tp53 (85\%) and SMAD4 (55\%) mutations are found in PanIN-3. Since PanINs represent precancerous ductal lesions, these mutations are considered early molecular biomarkers for PC [15]. A combination of biomarkers (EGFR, ERK, SIAH, Ki67 and HIF- $\alpha$ ) can predict survival rates for patients with resectable PC. In fact, a combination of these biomarkers is more strongly associated with pathological features including tumor size, tumor grade, margin and lymph node status compared to a single marker [7, 16, 17]. In a multicenter study, to differentiate PC from chronic pancreatitis and their benign controls, mucin (MUC5AC) alone or in combination with CA19-9 could be a potential diagnostic/prognostic biomarker [18].

Due to generic symptoms (weight loss, fatigue, jaundice, abdominal pain and nausea) common across multiple other pathologies, early identification of $\mathrm{PC}$ is difficult $[19,20]$. Recent studies suggest that PC develops from a precursor lesion of $<5 \mathrm{~mm}$ in diameter and may take an average of 20 years to metastasize [20]. Therefore, it provides a window of opportunity to diagnose and treat PC if it is detected at an early stage [21]. To date, efforts are being made in multiple directions to develop early diagnostic test for PC including histopathological tests on fine needle aspirates, serological tests, imaging (computed tomography/magnetic resonance imaging), and analysis of genetic mutation markers [21-23]. Regarding PC treatment, gemcitabine (a nucleotide analogue) is the preferred first-line option but survival is often less than $\sim 5$ months. Combination therapy with gemcitabine and erlotinib (an inhibitor of EGFR) increased the 1-year survival rate to $23 \%$ as compared to $17 \%$ in the gemcitabine plus placebo group in a randomized phase III clinical trial [24]. Other drugs such as folfirinox/nab-paclitaxel with gemcitabine also increase survival [25-27]. In a clinical trial, metastatic PC patients were treated by administration of folfirinox (5-fluorouracil with leucovorin, irinotecan, and oxaliplatin) had shown greater efficacy for metastatic cancer; however, few limitations were observed due to its cytotoxicity [28]. However, in a systematic study, over 30 years (from 1986 to 2016) weighted median overall survival was improved with folfirinox alone [3]. In addition to the above chemotherapeutic agents, different treatment options for PC patients includes Capecitabine and 5-fluorouracil (5-FU) along with platinum-based or other cancer drugs (leucovorin, exatecan, and irinotecan) [27]. Therefore novel treatment strategies are needed to improve the overall survival in PC patients.

\section{Obesity, insulin resistance and diabetes}

Obesity has become a serious threat worldwide and is considered an epidemic. It occurs due to changes in lifestyle (physical inactivity, intake of high fat/caloric diet, high sugar diet) and is also associated with lifestyle including cigarette smoking and alcohol consumption. Additionally, genetic factors such as mutation in the leptin pathway leads to monogenic obesity while chromosomal abnormalities results in syndromic obesity [29]. In the body, adipose tissue (AT) plays an important role in the storage of triglycerides (TG), which come from the diet. It is classified as brown and white AT, where brown AT (BAT) is predominantly located in the cervical area and utilizes TG to generate heat (a process called as thermogenesis). Disappearance of BAT has been observed during the aging process and recently it has gained significant attention. White AT is present in the subcutaneous layer, omentum and retroperitoneal cavity, where it stores excess fat. According to the lipid burden hypothesis, AT stores sufficient lipids in the form of droplets. Excess storage of lipids leads to hypertrophy (increase in cell size) and hyperplasia (increase in cell number) [30]. Moreover, in obesity, heavy traffic of lipids inside the body leads to release of excess TG in the form of free fatty acids (FFAs) into the circulation. Further, these FFAs accumulate in non-adipose tissues such as the pancreas, muscle, liver, heart and kidney, resulting in insulin resistance and diabetes [31].

Obesity is a multifactorial disease associated with several metabolic disorders including insulin resistance, glucose intolerance, dyslipidemia, and elevated blood pressure. All these disorders are collectively called metabolic X syndrome [32]. Further, obesity is a strong risk factor for type 2 diabetes mellitus (T2DM), cardiovascular diseases and even many types of cancers such as pancreatic, hematological, prostate and breast cancers [33]. Recent studies have revealed that obesity and PC are strongly associated. For instance, a body mass index greater than 35 is one of the risk factors for PC in both men and women [33, 34]. Moreover, studies have suggested that both obese mice and patients develop PC 
lesions following an increase in fat mass $[35,36]$ and show infiltration of fat cells in the pancreas as a consequence of PC development [37, 38]. Insulin resistance is a hallmark of T2DM, in which insulin fails to trigger adequate glucose uptake, leading to accumulation of circulatory glucose as well as increased insulin levels. These increased insulin levels in T2DM patients may be associated with PC growth by binding to its receptors located on the pancreas. For example, we still don't know if the insulin resistance that characterizes T2DM promotes $\mathrm{PC}$ or if the reverse is true (Fig. 1). In the present review, we have attempted to compress all the available literature on obesity-and diabetes-associated molecules involved in PC development. Several molecules have been characterized in obesity-associated PC, whereas less is known about factors unique to diabetes-associated PC. These molecules are expected to be the focus for future investigations of the molecular oncology of cancer.

\section{Obesity associated pancreatic ductal adenocarcinoma}

Obesity is associated with pancreatic and other types of cancers [39-41]. Individuals with abdominal adiposity have a 50\% increased risk of PC development compared to lean individuals [42]. In the U.S., about $70 \%$ of the adult population is overweight and has a two-fold increased risk of PC incidence and mortality [39, 42]. However, link between obesity and PC is still not fully understood [43]. The current theory is that excess TG in obesity leads to an increase in size and number of adipocytes, which results in devascularization, hypoxia, and ultimately macrophage infiltration. In this condition, adipocytokines including adiponectin, leptin, tumor necrosis factor-alpha (TNF- $\alpha$ ), interleukins, and monocyte chemoattractant proteins are secreted locally leading to inflammation. Evidence suggests that increased levels of adipocytokines, altered gut microbiota, and inflammation are involved in PC progression [39, 44]; thus, this review focuses on the possible oncogenic roles of these factors in PC.

\section{Adipocytokines}

Besides storing excess energy as TG, AT secretes several factors regulating energy metabolism in various organs. These adipokines including adiponectin, leptin, resistin, and ghrelin play an important role in glucose and lipid metabolism. Among them, adiponectin and leptin are the most important and are therefore the focus here in discussing obesity-associated PC.

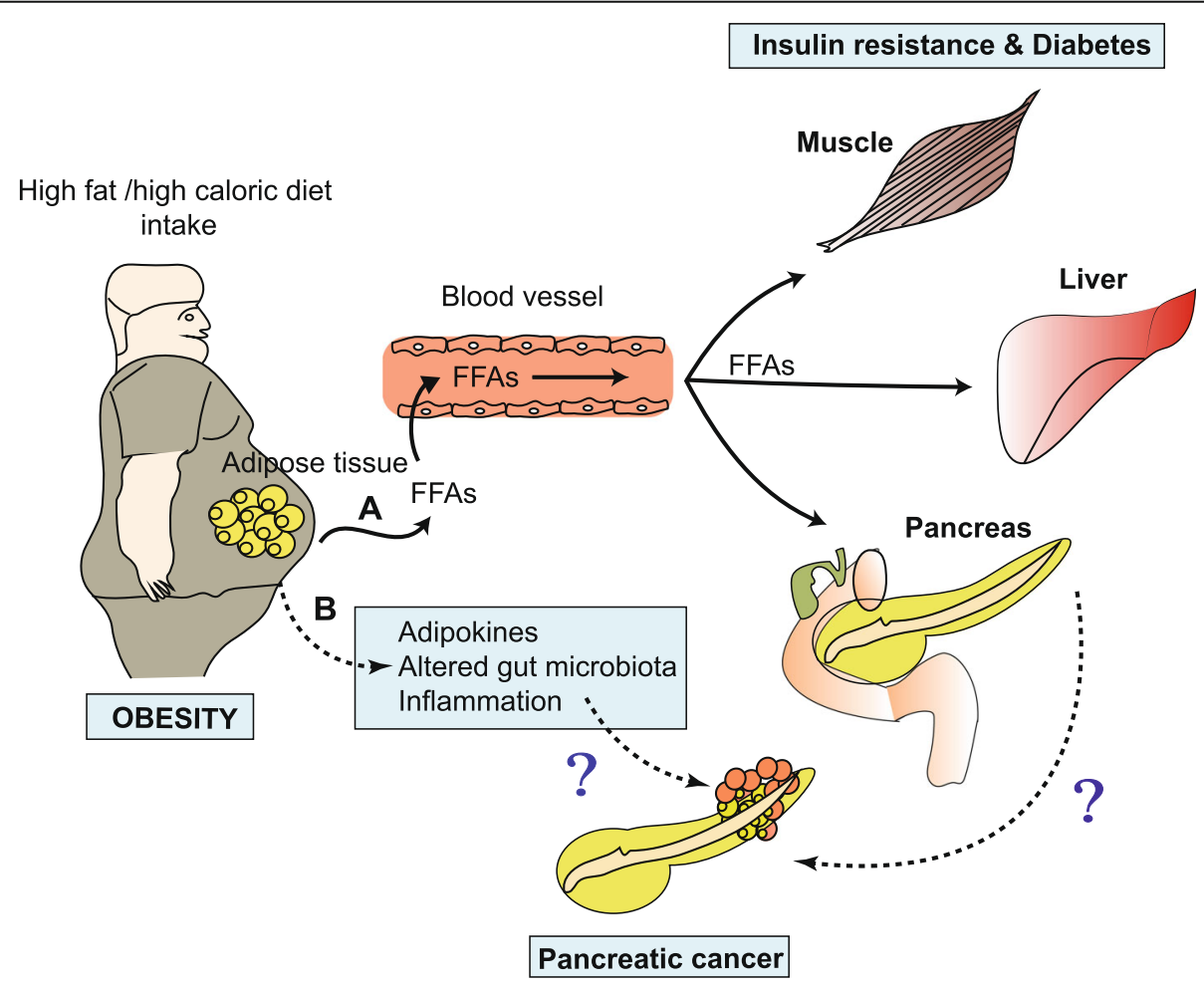

Fig. 1 A schematic representation of obesity- and diabetes-associated pancreatic cancer. High fat/caloric intake results in accumulation of excess fat, which further leads to development of obesity. a. In obesity, adipose tissue releases free fatty acids (FFAs), which enter circulation and accumulate in the non-adipose tissues such as muscle, liver and pancreas that leads to insulin resistance and diabetes. $\mathbf{b}$. Along with FFAs, adipokines, altered gut microbiota and inflammatory markers contribute to pancreatic cancer development through unknown mechanisms. 


\section{Adiponectin}

Adiponectin is also referred to as AdipoQ, which acts on several tissues to control energy homeostasis and insulin sensitivity $[45,46]$. It regulates carbohydrate as well as lipid metabolism through the adenosine monophosphate -activated protein kinase (AMPK) pathway. The expression of circulatory AdipoQ is decreased in obesity and diabetes. However, the role of circulating AdipoQ in PC remains debatable regarding its impact on pancreatic tumor progression. Adiponectin serve as negative regulator that mediate its function by acting on its two receptors i.e. AdipoR1 and AdipoR2. Mechanistically, AdipoQ increases insulin synthesis and secretion by preventing apoptosis of pancreatic $\beta$-cells through activation of ERK and AKT pathways [47] (Fig. 2). Huang et al. demonstrated that subcutaneous implant of mouse pancreatic cell lines (H7 and Panc02) in AdipoQ knockout (APNKO) mice has reduced tumor weight and size as well as increased apoptosis by up-regulating cleaved caspase- 3 as compared to wild type (WT) littermates. In addition, knockdown of AdipoR1, the major receptor of AdipoQ in these mouse cell lines (H7 and Panc02) followed by subcutaneous injection reduced tumor weight, size, and expression of Ki-67 (proliferation marker). Further, AdipoQ was observed to decreases apoptosis and increases PC cell proliferation and migration

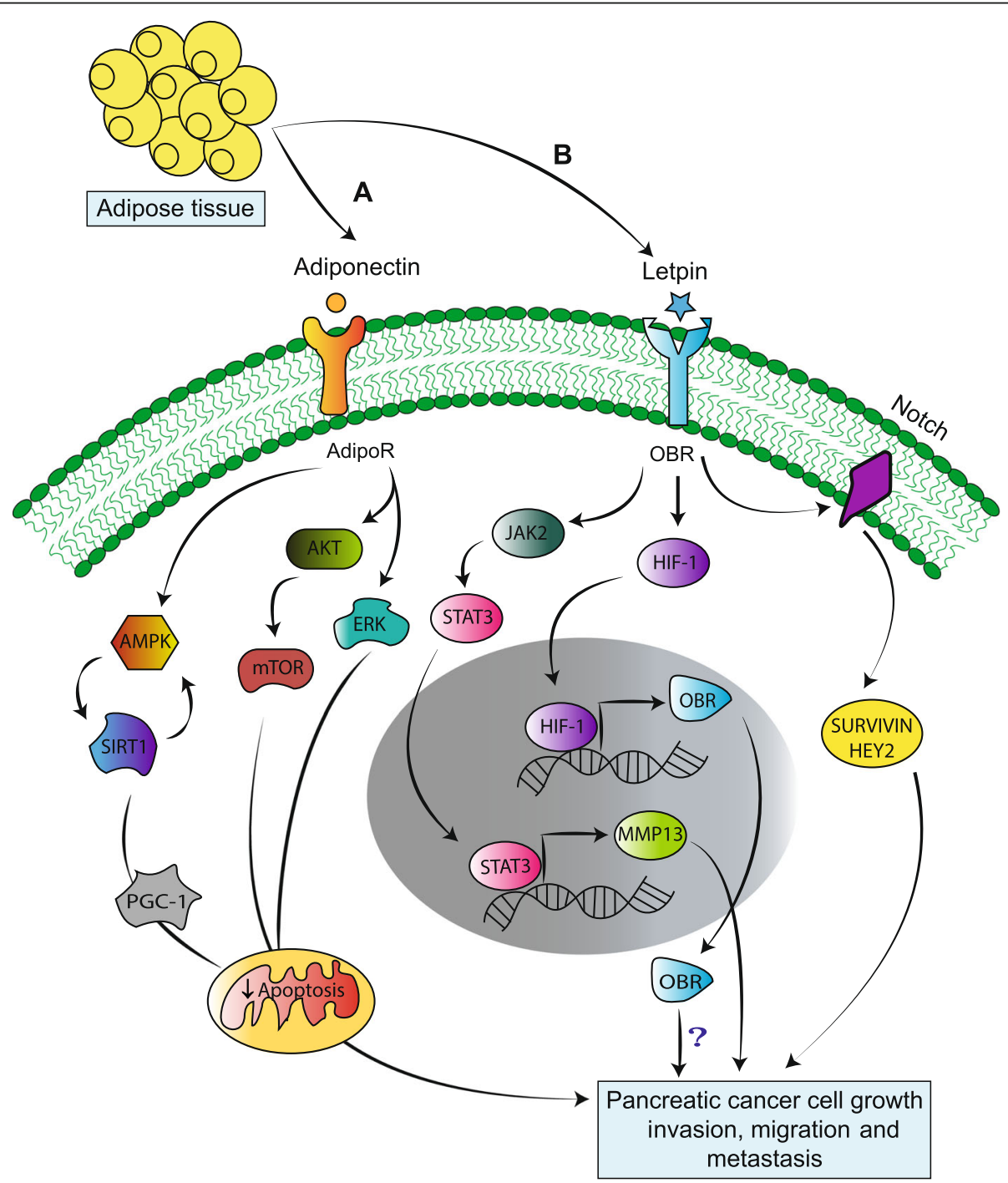

Fig. 2 Adipocytokines mediate pancreatic cancer tumorigenesis by different signaling mechanisms. a. Adiponectin secreted from adipose tissue binds to its receptor (AdipoR) to activate AKT, MAPK and AMPK pathways, which block the apoptosis of pancreatic cancer cells. b. Similarly, leptin binding to its receptor (OBR) results in activation of the JAK2/STAT3 pathway, which leads to matrix metalloproteinase-13 activation and eventual pancreatic cancer metastasis. In addition, OBR also regulates its own expression through hypoxia inducible factor-1, resulting in cancer cell survival via an unknown mechanism. Moreover, leptin also triggers Notch receptor signaling, which results in activation of its downstream molecules (survivin and Hey2), thereby increasing cancer cell proliferation. 
by activating the AMPK-Sirt1-PGC1 $\alpha$ pathway [48] (Fig. 2). Similarly, in a case-control study, Dalamaga et al. studied the blood levels of AdipoQ in PC and control cases both before and after controlling for age, gender, BMI, smoking status, alcohol consumption, history of diabetes, and family history of PC. Higher AdipoQ levels were associated with PC. At tissue level, utilizing 16 tumor tissues, the authors observed positive or strong positive expression of AdipoR1 in $87.5 \%$ of cases while positive or strong positive expression of AdipoR2 was observed in $>97 \%$ cases. Based on this, the investigators suggested to investigate the role of AdipoQ as a marker for early detection of PC. Further, Kadri et al. observed no correlation between adiponectin levels and PC [49]. Similarly, Pezzilli et al. did not observe any significant correlation among adiponectin levels and PC at serum level [50]. However, retrospective and prospective studies indicate that early detection of low circulatory AdipoQ levels may or may not be associated with the development of PC, because single nucleotide polymorphisms of the AdipoQ gene are common [51-54] and the presence of these SNPs in AdipoQ, but not its receptors, are associated with altered serum adiponectin levels [55].

Inhibitory role of AdipoQ in halting tumor progression has also been observed [49]. In this regard some clinical studies suggest that circulating AdipoQ inhibit tumor cell proliferation by decreasing AKT and beta catenin levels across multiple malignancies (breast, colon and prostate) $[56,57]$. In the case of $\mathrm{PC}$, the molecular mechanism by which up-regulated AdipoQ levels inhibit cancer progression is still unclear; possibilities include 1) increasing insulin sensitivity via phosphorylation of insulin receptors, which down-regulates insulin/IGF-1 signaling, 2) down-regulating the expression of inflammatory cytokines that inhibit NF- $\mathrm{kB}$ activation, 3) directly activating the AMPK pathway to activate the p53 tumor suppressor gene, and 4) promoting cancer cell apoptosis via peroxisome proliferator-activated receptor gamma (PPAR $\gamma$ ) activation and inhibiting angiogenesis $[58,59]$. One study fed genetically engineered PC mice (Kras $\left.{ }^{\mathrm{G} 12 \mathrm{D}} / \mathrm{Pdx}-1-\mathrm{Cre}\right)$ with a calorie-restricted diet and observed delays in formation of pancreatic intraepithelial neoplasms (PanIN) [60, 61]. Delayed progression of PanIN to PDAC was accompanied by increased AdipoQ and Sirt1 levels as well as decreased mTOR and IGF-1 expression [61]. In another study, Kato et al. incubated recombinant AdipoQ with the Pan02 murine cell line and noted decreased cell proliferation and increased apoptosis at 5 and $10 \mu \mathrm{g} / \mathrm{ml}$, respectively. Further, orthotopic implantation of Pan02 cell line showed a significant increase in tumor volume by higher vascularization (more microvessel density) and decreased apoptosis in AdipoQ knockout mice as compared to WT animal $[58,62]$. Overall, the findings from this study suggested AdipoQ to be a tumor suppressive role in PC by directly inhibiting proliferation and inducing apoptosis [62]. Interestingly, a recent study by Messaggio and co-workers showed that the decreased expression of AdipoQ receptors in pancreatic tumor tissues as compared to adjacent normal tissue. To elucidate the role of AdipoQ, its agonist AdipoRon was applied to both mouse and human cell lines and was found to inhibit PC tumor growth and proliferation by down-regulating leptin-induced STAT3 signaling. These results suggest AdipoRon could be a potential therapeutic agent for PC [63].

\section{Leptin}

Leptin was the first adipokine identified in AT in 1993; it controls food intake and energy expenditure via a feedback mechanism in the brain [64]. After secretion from AT, leptin enters into circulation and reaches a level depending upon the AT size [65]. Under normal physiological conditions, leptin decreases appetite and increases fatty acid oxidation through its receptor (OBR or LEPR). However, in obesity and diabetes, elevated circulatory levels of leptin do not drive the same appetite feedback responses [66]. Like AdipoQ, leptin has a role in PC pathogenesis. In PC tumor cells, leptin binds to both full-length receptor (OBR1) as well as the short form (OBRs) to mediate downstream signaling [67]. Leptin receptor (OBR) and hypoxia inducible factor-1 (HIF-1) are predominantly co-expressed in PC cell lines and tissues during hypoxic conditions. HIF-1 binds to the hypoxia-responsive element (HRE) in the OBR promoter, regulating OBR transcription. Co-expression of OBR and HIF-1 in PC tissues was associated with poor prognosis, decreased overall survival and increased metastasis to distant organs in PC patients (Fig. 2). Silencing of HIF-1 inhibited leptin receptor expression in $\mathrm{PC}$ cells, suggesting that a positive feedback loop between HIF-1 and leptin/OBR mediates PC progression [67]. In another in vitro study, recombinant human leptin promoted PC cell migration and invasion but had no effect on proliferation [68]. The migration of PC cells occurred via the janus kinase 2 and signal transducer and activator of transcription 3 (JAK2/STAT3) pathway, which targets its downstream effector matrix metalloproteinase 13 (MMP13). The in vivo impact of leptin-over expressing PC cells was tested by orthotopic implantation into athymic nude mice, which led to greater tumor growth and lymph node metastasis. Over expression of leptin in PC cells and mouse tumors resulted in up-regulation of MMP13 levels, suggesting that leptin/MMP13 signaling is important for metastasis. In addition, MMP13 levels correlated with OBR expression in lymph node metastatic human PC tissues. The authors concluded that PC cell migration, invasion and 
metastasis occur via the JAK2/STAT3/MMP13 pathway [68] (Fig. 2).

A high fat/caloric diet leads to obesity, insulin resistance and increased leptin levels, all of which contribute to pancreatic adiposity. The accumulation of lipid molecules into the pancreas leads to activation and deposition of inflammatory cytokines (e.g., interleukin-6), which potentiate PC cell growth, migration and invasion [69]. Leptin activates Notch signaling and its receptors, leading to activation of its downstream molecules (survivin and Hey2) required for PC proliferation (Fig. 2). Notch signaling also up-regulates stem cell markers (CD44, CD24 and ESA) in PC cells. Inhibition of leptin (by IONP-LPrA2) after subcutaneous implantation of PC cells delayed tumor onset and decreased tumor size as well as cancer stem cell markers [70]. In another study by the same group reported that $\mathrm{BxPC}-3$ and MiaPaCa-2 PC cells were treated in the presence of 5-FU, leptin, notch inhibitor (DAPT) and leptin inhibitor (IONP-LPrA2). They observed that decreased 5-FU cytotoxicity (by decreasing pro-apoptotic markers), increased cell proliferation and anti-apoptotic factors was due to leptin treatment. Moreover, IONP-LPrA2 reduced PC tumorspheres (treated with 5-FU) via notch signaling and suggesting that leptin might be involved in reducing the cytotoxic effect of chemotherapeutic drug and facilitating chemoresistance [71]. The leptin-notch signaling axis targeting has been projected as potential mediator for benefitting PC patients with obesity. Overall, the effect of AdipoQ and leptin in the progression of $\mathrm{PC}$ is still under investigation in obese people and further studies are warranted before targeting these adipokines in PC therapy.

\section{Gut microbiota and inflammation}

The gut microbiome (hidden organ) comprises at least $10^{14}$ microorganisms belonging mostly to the phyla Firmicutes and Bacteroidetes, which play an important role in obesity and other metabolic disorders [72]. Recent evidences suggest that diet, environmental factors and microbial components can contribute to the development of cancer in liver and pancreas through a gut-liver/pancreas axis [73]. As shown in Fig. 3, a high-fat diet can alter the gut microbiome and trigger an inflammatory cascade. Gram-negative bacteria secrete lipopolysaccharide (LPS), which induces low-grade inflammation through its binding to toll-like receptors (TLRs) and CD14 co-receptors present on monocytes, macrophages and neutrophils [74, 75]. Furthermore, altered gut microbiota may lead to decreased intestinal tight junction proteins (ZO-1 and occludin), which allows LPS entry into circulation [76]. Binding of LPS to its up-regulated receptors (CD14 or TLRs) on immune cells induces PC cell proliferation [77, 78]. Additionally, these immune cells also play a role in cancer cell invasion, angiogenesis and metastasis [79-81] by recruiting myeloid differentiation primary response gene 88 (MyD88) or TIR-domain-containing adapter-inducing interferon- $\beta$ (TRIF) adaptor molecules. Activation of these molecules leads to inflammation by up-regulating p44/42 mitogenactivated protein kinase/extracellular signal-regulated kinase (MAPK) and NF- $k B$ pathways (Fig. 3). Therefore, an altered gut microbiota may promote cancer by driving inflammatory responses [82]. In support of this, germ-free (absent microflora) mice are less prone to carcinogenesis probably due to a decrease in tumorassociated inflammation [83, 84]. Similar results were observed when WT mice were treated with broadspectrum antibiotics to inhibit the microbiota [85]. As final evidence, antigenic peptide secreted from Helicobacter pylori (which causes gastric ulcers) has been associated with PC pathogenesis [86]. H. pylori components translocate into the pancreas from the gut and activate NF- $\mathrm{KB}$, thereby increasing the expression of pro-inflammatory cytokines involved in PC initiation and progression [87]. A recent study by Sethi et al. demonstrated that the gut microbiome modulation may have impact on tumor growth in a mouse model. Initially, the authors orally administered a cocktail of broad-spectrum antibiotics to C57BL/6J mice for 15 days. Then at 15 days, a pancreatic cell line derived from $\mathrm{Kras}^{\mathrm{G12D/+} \text {; }}$ $\operatorname{Trp} 53^{R 172 H /+} ; P d x 1^{\text {cre }}$ (KPC) mice was injected subcutaneously or intrasplenically (to induce liver metastasis). Results of this study showed that absence of gut microbiota led to a significant decrease in subcutaneous tumors, and decreased degree of liver metastasis. Besides, an absence of gut microbiota shows a significant increase in anti-tumor mature $\mathrm{T}$ cells [Th1 (IFN gam$\mathrm{ma}^{+} \mathrm{CD}_{4}^{+} \mathrm{CD}^{+}$) and Tc1 cells (IFN gamma ${ }^{+} \mathrm{CD}^{+} \mathrm{CD}^{+}$)] in the tumor microenvironment with an unknown mechanism. Finally, the relative abundance of Bacteroidetes and Firmicutes phyla decreased in fecal samples upon antibiotic administration in KPC mice. The authors concluded that modulation of gut microbiota on tumor progression could be a novel immunotherapeutic strategy [88].

In general, pancreatic tumors depend on carbohydrate metabolism for their survival, growth and resistance to chemotherapy. Dietary carbohydrates are usually fully metabolized in the small intestine, with the exception of resistant starch. Gut microbiota further process the starch in the large intestine through fermentation, and as a result, short-chain fatty acids (acetate, butyrate and propionate) are released. Resistant starch by avoiding degradation in small intestine imparts several health benefits via decreasing circulatory glucose levels, body weight, and inflammation without causing any side effects [89]. Interestingly, media engineered to mimic resistant starch (low glucose concentration) decreased PC cell proliferation compared 


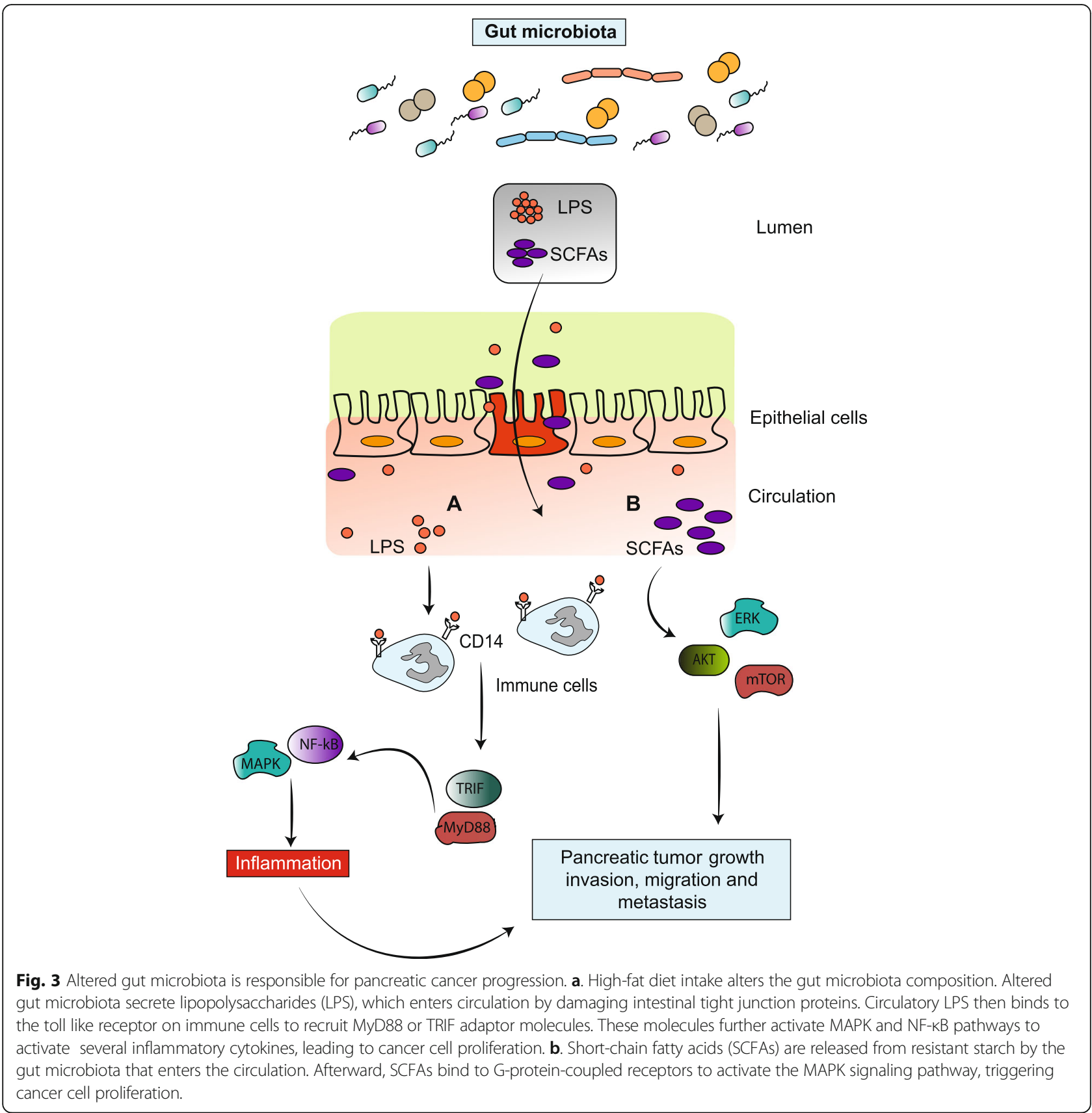

with control media. The decrease in cell proliferation is due to down-regulation of ERK and mTOR signaling (Fig. 3). Similarly, mice bearing sub-cutaneous PC tumors fed a resistant starch diet showed lower tumor weight than controls on a normal diet. Additionally, resistant starch also inhibits the growth of inflammation-causing organisms including Bacteroides acidifaciens, Ruminococcus gnavus, Clostridium cocleatum and Escherichia coli in mice by modulating gut microbiota [90].

Early metastasis (primarily at lymph nodes and liver) and chemoresistance are responsible for PC aggressiveness.
However, treatment with gemcitabine, first line therapy for metastatic PC, results in altered gut microbiota, which affects PC growth. Administration of gemcitabine in nude mice bearing subcutaneous PC cell line tumors leads to increased growth of Proteobacteria and Akkermansia muciniphila, which potentiate inflammation and/or mucin degradation. The imbalance of gut microbiome due to gemcitabine treatment also disrupts the intestinal integrity; this, in turn, favors the entry of microorganisms or their components into the circulation to reach distant organs. In the pancreas, the microbe-associated molecular patterns (such as LPS and endotoxins) on the microbial surfaces bind to 
TLRs, activating inflammation through NF-kB signaling. In addition, gemcitabine-treated mice have greater LPS-induced inflammation and lower levels of inosine (a naturally occurring metabolite of adenosine), which has anti-inflammatory and immunosuppressive effects [91]. Furthermore, fecal microbiota obtained from KPC mice was recolonized into antibiotic treated WT mice which shows higher bacterial population access into the pancreas. Ablation of gut microbiota in Ptfla ${ }^{\mathrm{Cre}}$; LSL-Kras ${ }^{\mathrm{G} 12 \mathrm{D}}$ (KC) mice by oral antibiotics were recolonized with feces derived from WT or KPC mice and pancreatic tumor growth acceleration was observed in KPC derived feces only. Similarly, recolonization of feces (from KPC animal bearing pancreatic tumors) in germ free (GF)-KC mice shows increased pancreatic tumor growth as compared to GF-WT mice. This tumor acceleration might be associated with a decrease in activated T-cell infiltration in GF condition. They hypothesized that antibiotic treatment results in an increased intratumoral CD8:CD4 T-cell ratio which activates immunogenicity in PC. Future studies are warranted to identify microbial signatures that influence growth of PC tumors [92]. Taken together, a better understanding of the role of gut microbiota in PC tumor progression could open up new avenues in PC therapy development.

In obesity, pro-inflammatory cytokines are released from AT macrophages and infiltrate into AT; however the exact mechanism for these events is not known. In obese rats and humans, elevated inflammatory cytokine TNF- $\alpha$ activates other cytokines, in particular, IL-6, promoting angiogenesis and metastasis [93-95]. Therefore, the possible common mechanism by which obesity induces inflammation in several cancers (pancreatic, lymphoma and glioblastoma) might be through TNF- $\alpha$-induced NF- $\kappa B$ signaling [96-98]. In addition, TNF- $\alpha$ secreted from cancer cells triggers cancer associated fibroblasts to stimulate macrophage infiltration [99, 100]. This infiltration occurs in several cancers through TNF- $\alpha$-induced IL- 6 to up-regulate STAT3 signaling [101]. Mice with PC tumors and diet-induced or genetic obesity expressed significantly higher STAT3 in the PC tumors. The up-regulation of STAT3 can drive PC progression through the activation of anti-apoptotic and proliferative proteins $\left(\mathrm{Bcl}-\mathrm{X}_{\mathrm{L}}, \mathrm{Mcl}-1\right.$, Survivin, c-Myc and cyclin D1) as well as matrix metalloproteinases [102-104]. Currently, studies are focused on the role of AT-derived inflammatory cytokines in modulating signaling pathways that can indirectly influence the progression of PC.

\section{Glucose metabolic enzymes}

Despite the harsh hypoxic environment, PC survives in part due to expression of HIF1- $\alpha$, which prevents apoptosis and increases the synthesis of glycolytic enzymes and transporter proteins [105]. According to the Warburg effect, the cancer cell depends on glycolysis to produce energy instead of aerobic respiration [106-108]. The most important rate-limiting glycolytic enzymes are pyruvate kinase (PKM2), which catalyzes the conversion of phosphoenol pyruvate to pyruvate, and lactate dehydrogenase (LDHA), which then catalyzes conversion of pyruvate to lactate. The glycolytic pathway releases high-energy phosphates in the form of nicotinamide adenine dinucleotide, which enters the mitochondria for energy synthesis. LDHA is overexpressed throughout carcinogenesis, while PKM2 expression increases during the transition of cystic lesions to cancer. A possible explanation is that cystic lesions require high levels of LDHA, which induces PKM2 splicing in a later stage of tumor proliferation [109]. Furthermore, activation of EGFR initiates translocation of PKM2 to the nucleus where it binds to $\beta$-catenin, resulting in up-regulation of cyclin D1, Stat3, Oct4 and HIF, which induce cell proliferation $[110,111]$. Therefore, both glycolytic enzymes (PKM2 and LDHA) are possible targets for PC treatment in preclinical studies.

\section{Hepatocyte growth factor}

In addition to adipokines, pre-adipocytes as well as mature AT secrete cytokines and growth factors that have a role in tumor growth. In pancreatic tumor progression, cross-talk between PSC and PC is mediated through several growth factors including platelet-derived growth factor, transforming growth factor, vascular endothelial growth factor and hepatocyte growth factor (HGF) [112, 113]. HGF has received much attention due to its mitogenic signal and its angiogenic effects on AT $[114,115]$. In the case of obesity, HGF is released from the AT and the resulting circulatory levels contribute to pancreatic cell proliferation [116]. Exogenous supplementation of HGF induces proliferation in a murine pancreatic cell line (Pan02) through its receptor c-MET, whereas in the absence of c-MET, HGF had no direct effects in a murine pancreatic cell line and indirectly inhibited apoptotic cell death [117]. HGF inhibition by means of neutralizing antibody (AMG102) inhibited tumor growth and metastasis as compared to gemcitabine treatment [118]. Over expression of c-Met renders PC cells resistant to gemcitabine and radiation [44, 119] through an unknown mechanism. As one possibility, Cui and co-workers demonstrated that the Forkhead box M1 (FOXM1) transcription factor regulates c-MET expression via ERK, AKT and STAT3 pathways, creating a positive feedback loop that promotes tumor growth. Further, inhibition of c-MET, FOXM1, ERK, AKT and STAT3 signaling pathways with their respective inhibitors abolished the c-MET positive loop [120]. Therefore, the HGF/c-MET feedback loop regulates tumor 
proliferation, invasion and migration [121] and may be a novel target for growth factor-induced tumor growth.

\section{Hyaluronan}

In obesity, TG accumulates in the pancreas along with other organs and results in inflammation, higher expression of cytokines and remodeling of extracellular matrix (ECM). Hyaluronic acid or hyaluronan (HA) is a glycosaminoglycan and ubiquitous component of ECM which increases interstitial fluid pressure (IFP) and also reduces entry of chemotherapeutic drugs in PC tumors [122]. In tumor progression, the cross-talk between cancer cells and ECM is very important. Normally, HA synthesized by hyaluronan synthase (HAS) and secreted into the ECM under controlled conditions. However, increased expression of HA was observed in insulin-resistant mice aorta [123] and in the pancreas of diabetic mice [124]. In addition, expression of HA in the ECM is associated with diet-induced insulin resistance and was reversed upon treatment with the drug pegylated recombinant human hyaluronidase (PEGPH20), which improves insulin sensitivity in muscle tissue [125].

The PC stroma cells and the ECM express abundant HA to maintain a supportive tumor microenvironment [126]. Binding of HA to its receptors [cluster of differentiation-44 (CD44) or receptor for HA-mediated motility (RHAMM)], activates Ras and PI3K signaling, leading to increased cell proliferation, migration, and metastasis. Further, the activated PI3K pathway in cancer cells also increases drug resistance via activation of a multi-drug receptor [127-129]. The HA receptor CD44/ RHAMM mediates cell-cell/matrix interactions and up-regulation of HA (around 12-fold increase) is observed in PC [130-133]. PC cells increase expression of HA via epigenetic regulation (decreased DNA methylation) and concomitant up-regulation of its enzyme HAS [134]. HA exists in low and high molecular weight forms. In vitro treatment with low molecular weight HA (25-75 kDa) increased PC cell motility compared to treatment with high molecular weight HA (400-600 $\mathrm{kDa})[135,136]$. In conclusion, inhibition of HA synthesis may be a possible therapeutic strategy against $\mathrm{PC}$ and obesity-associated PC. Recently, PEGPH20 has gained interest to target HA for improving intratumoral microenvironment in PC. The different concentrations of HA along with mouse PC cells were implanted in immunodeficient mice that showed high IFP which reduce delivery of chemotherapeutic drugs. So targeting HA, a single high dose of PEGPH20 had a significant reduction on IFP in KPC mice. Further, a combination of PEGPH20 and gemcitabine showed decrease in cell proliferation and increased apoptosis in KPC mice [137]. In a randomized phase II clinical study, metastatic PC patients (231 were selected from a total of 279 patients) were treated with nab-paclitaxel/gemcitabine (AG) or PEGPH20 + nab-paclitaxel/gemcitabine (PAG). Patients $(\mathrm{n}=84)$ who had HA-high tumors showed improvement in the progression-free survival, overall survival and reduction in the thromboembolic (TE) incidence by PAG alone. Furthermore, PAG treatment was accompanied by more muscle spasm, neutropenia, myalgia and TE as compared to AG. Overall, srudy finding suggested that tumor HA could be a promising therapeutic target for PC patients with high HA [138].

\section{Diabetes mellitus associated pancreatic ductal adenocarcinoma}

Obesity is associated with insulin resistance and T2DM, which in turn is a potential risk factor for PC. In a post-prandial state, insulin maintains the levels of circulating glucose and FFAs. Insulin resistance is a condition in which the adipose and muscle tissues and to a lesser extent the pancreas, brain, liver and kidney are unable to respond to insulin. Insulin resistance is a hallmark of T2DM, leading to down-regulation of insulin signaling pathways (at the post-receptor level) in these tissues [139]. Of the diabetic population, $12 \%$ are diagnosed with type 1 diabetes, $80 \%$ with T2DM, and $8 \%$ with pancreatic diabetes (acute and chronic) [140]. About $80 \%$ of the PC population have insulin resistance or frank diabetes and are diagnosed at the metastasis stage. However, recent-onset diabetic patients developing diabetes at later age (average age greater than or equal to50) accompanied with weight loss and exceesive exocrine damage (PC associated diabetes mellitus) were higher risk for PC than long term diabetic population [141]. Pharmacological therapies like metformin (lowers blood glucose and insulin levels), sulfonylurea (promotes secretion of insulin from the pancreas) and insulin analogues (glargine) are available to treat diabetes [142, 143]; however these treatments often fail after prolonged usage. However, a case-control study at M.D. Anderson Cancer Center from 2004 to 2008 recruited 973 PDAC patients among them 259 were diabetic. The diabetic patients who received metformin had a lower risk of PC compared to those who were not given metformin; whereas, insulin or insulin secretagogues administered diabetic patients had a higher risk of PC [144].

As mentioned, T2DM is also a major risk factor for several cancers including PC. Epidemiological studies indicate that T2DM patients have a 1.8-fold increased risk for PC development [145]. However, the literature suggests that insulin resistance and diabetes may be a consequence of PC (up to $50-80 \%$ of cases). Clinical studies reveal that $0.85 \%$ ( 8 out of 2122 ) to $7 \%$ (6 out of 86) of diabetic patients were first diagnosed with PC $[146,147]$. In PC, the increase in circulatory FFAs secreted from AT causes lipotoxicity in $\beta$-cells, resulting in 
PC-associated diabetes mellitus (PCDM) [145, 148, 149]. After tumor resection, the increased survival of PC patients was associated with greater insulin sensitivity [150]. Recently, the American Diabetic Association classified PCDM, which is induced by chronic pancreatitis and pancreatic surgery, as type3c diabetes mellitus [151]. Still, evidence describing how diabetes leads to PC or vice versa is lacking. Some of the key molecules secreted from AT are being considered for the treatment of PCDM, which we focus on below.

\section{Adrenomedullin and extracellular vesicles (exosomes)}

Adrenomedullin (AM) is expressed by F-cells of the pancreas and plays a role in PC along with its receptor (adrenomedullin receptor ADMR). In 1993, AM was initially isolated from an adrenal medulla tumor called a pheochromocytoma. It is also expressed in AT and acts on pancreatic $\beta$-cells to inhibit insulin secretion; however, its effects on $\beta$-cells are poorly understood [152]. The circulatory levels of AM are very low under normal conditions; however, its levels are elevated in PC to cause insulin resistance [153]. Pancreatic beta, endothelial and stellate cells express ADMR. Its autocrine function in modulating tumor growth and progression has been evaluated in certain PC cell lines, i.e. Panc-1, BxPC3, and MPanc96 as well as human PSC and endothelial cells [154]. In a study, treatment with AM antagonist reduced PC tumor growth which indicating that AM plays a role in promoting PC progression. Furthermore, silencing of ADMR inhibited tumor growth and metastasis in liver and lung tissues of xenograft mice [155]. In PCDM, plasma levels of AM were significantly higher compared to diabetic patients alone, and its expression is higher in tumor and hypoxia conditions $[152,156]$.

AM is transported in the pancreas by extracellular vesicles, which contain proteins, lipids, and nucleic acids and are secreted by all cell types into circulation [157]. These vesicles play an important role in the transportation of biological components to other cells and tissues [158]. Extracellular vesicles form exosomes (30-100 nm) by inward or reverse budding of vesicular bodies called microvesicles (100-1000 $\mathrm{nm}$ ) or by outward blebbing of membrane and apoptotic bodies (500-2000 nm) [159, 160]. Exosomes derived from PC cells have the capacity to promote metastasis in a tissue such as liver by residing in a pre-metastatic niche. The niche contains macrophage migration inhibitory factor engulfed by Kupffer cells, which induces secretion of fibronectin in the liver. The secreted fibronectin inhibits infiltration of macrophages and neutrophils derived from the bone marrow and promotes tumor growth [161]. PC exosomes control the specific site of organ metastasis by producing integrins, molecules that mediate cell adhesion. For example, Kupffer, lung fibroblast and epithelial cells recognize integrins such as $\alpha v \beta 5, \alpha 6 \beta 1$ and $\alpha 6 \beta 4$, respectively, and subsequently recruit PC cells to these organs [162]. PC exosomes can also transfer AM to pancreatic $\beta$-cells (via caveolin-dependent endocytosis and micropinocytosis), which causes insulin resistance through ADMR-AM interactions. Furthermore, the presence of exosomal AM results in $\beta$-cell damage by increasing the production of reactive oxygen/nitrogen species and by increasing endoplasmic reticular stress markers (Bip and Chop) [163]. PC cell exosomes containing AM enter AT by the same mechanism that occurs in pancreatic $\beta$-cells. Internalization of AM results in lipolysis by activation of hormone-sensitive lipase through p38 and MAPK/ERK pathways; the resulting effect is growth and differentiation of the cancer cells [164]. Another similar peptide to $A M$ is $A M-2$, which was identified in rats in 2004. AM2 has a similar function as AM in promoting angiogenesis, tumor development, progression and metastasis through MAPK signaling [165]. However, no studies have examined the role of AM-2 in PCDM.

\section{Vanin and matrix metalloproteinase}

Another important molecule is vanin 1 (VNN1, pantetheinase) present on the surface of epithelial and myeloid cells and highly expressed in the gut and liver tissue $[166,167]$. VNN1 is mainly responsible for the breakdown of pantetheine to pantothenic acid (vitamin $\mathrm{B}_{5}$ ) and cysteamine [168]. It is actively involved in inflammation, migration, stress, and glucose and lipid metabolism. Alteration of glucose and lipid metabolic pathways in the liver leads to development of insulin resistance and eventual T2DM. Mice exhibiting diet-induced obesity and Zucker diabetic fatty rats (model for T2DM) have more VNN1 activity in plasma as well as higher expression in the liver compared to normal controls [169]. Based on gene expression profiling, PCDM patients express higher VNN1 and MMP9 levels in peripheral blood as compared to patients with T2DM alone [170]. VNN1 reduces inflammation in PCDM by altering the levels of cysteamine and glutathione. VNN1 along with cysteamine protect the pancreatic $\beta$-cells from the oxidative stress generated during streptozotocin-induced diabetes in animals [171]. Enhanced $\gamma$-glutamylcysteine synthetase activity observed in vanin $-1^{-1-}$ deficient mice with low levels of cysteamine resulted in an accumulation of endogenous glutathione (GSH) levels $[172,173]$. By contrast, over expression of VNN1 decreased expression of GSH and PPARy, resulting in increased oxidative stress in PCDM [174], through an unknown mechanism. These findings suggest that decreased GSH and PPAR $\gamma$ might contribute to islet dysfunction in PCDM and that vanin-1 and MMP9 could serve as novel pharmacological targets to treat early asymptomatic PCDM patients. 


\section{Impact of obesity and diabetes on acinar, ductal and islet cells}

The pancreas islets, acinar cells, and ducts of the gland make up approximately $2-3 \%, 85 \%$ and $5 \%$ of the volume, respectively. Similar to other organs, pancreas size is regulated by genetic as well as environmental factors (food intake) [175]. Feeding chronic high fat diet to Zucker diabetic fatty rats (model for both obesity and T2DM) showed excessive fat accumulation in pancreatic acinar cells and later resulted in acinar cell injury and pancreatic fibrosis [176]. In another study, feeding high fat or high calorie-diets to $P d x-1^{\mathrm{Cre}}$ and LSL-Kras ${ }^{\mathrm{G} 12 \mathrm{D}}$ mice caused increased PSC activation, stromal fibrosis and infiltration by inflammatory cells [177]. In case of T2DM, both islets and peri-islet exocrine tissue of pancreas have an activated PSC. The activated, as well as quiescent PSC express receptors for insulin and insulin-like growth factor, however in activated PSC; insulin enhances cell proliferation and production of extracellular matrix proteins as compared to quiescent PSC [178]. Moreover, obese and T2DM patients show a ten-folds and four-folds increase in pancreatic ductal cell replication (more Ki67 expression), respectively. The increased pancreatic ductal cell replication is a risk factor towards pancreatitis and pancreatic cancer in obesity and or type 2 diabetes subjects [179].

\section{Obesity and diabetes associated PC stem cells}

Studies are suggesting that tumor initiation, progression, and resistance to chemotherapy is due to the presence of a small subset of a cell population within the tumor called cancer stem cells [180-182]. The presence of stem cell markers in normal pancreas might be involved in the progression of PC and resistance to drugs [183]. In obesity, leptin treatment affected $\mathrm{PC}$ progression and increased pancreatic cancer stem cell markers such as CD24/CD44/ ESA, ALDH, CD133, and Oct-4. Further, the expression of leptin receptor was decreased by tumor suppressor micro RNAs that specifically target pancreatic stem cell markers (Met, ABCB1, and CD44) to reduce their expression [184]. Leptin is also involved in the growth of PC tumorspheres and resistance to the chemotherapeutic drug (gemcitabine) [185] by increasing the stem cell markers (CD24, CD44, ESA, CD133, and ALDH) in MiaPaCa-2 PC cell line. Additionally, leptin up-regulates the expression of $\mathrm{ABCB} 1$ (an ATP binding transporter protein) in PC tumorspheres suggesting its role in stem cell stimulation and chemoresistance [70]. In case of diabetic population, hyperglycemia is a hallmark of T2DM which stimulates PC by promoting a epithelial to mesenchymal transition and expression of pluripotency stem cell markers (Sox2, Oct4, and Nanog) via activating transforming growth factor-beta 1 [186]. Further, studies are needed to understand the exact molecular mechanisms involved in metabolic diseases associated with PC stem cells.

\section{Conclusions}

Several studies suggest that obesity and T2DM increase the risk for PC development and its pathogenesis. However, mechanistic interplay responsible for development and progression of pancreatic tumor remains obscure. Recent studies on key players associated with obesity and diabetes such as adipocytokines, gut microbiota, adrenomedullin, hyaluronan, vanin and matrix metalloproteinase have deciphered unknown linkage present across PC as well as PCDM. These mediators play central role in promoting obesity-and diabetes-associated pancreatic cancer, however, to date studies involving therapeutic targeting and harnessing their biomarker potential are still in infancy. Henceforth, based on literature survey, we suggest that there is an urgent need to delineate biomarkers as well as therapeutic target(s) involved in the obesity and T2DM associated PC development making inroads to prevent this highly lethal malignancy.

\begin{abstract}
Abbreviations
AdipoQ: Adiponectin; ADMR: Adrenomedullin receptor; AG: Nab-paclitaxel/ gemcitabine; AM: Adrenomedullin; AMPK: Adenosine monophosphate-activated protein kinase; AT: Adipose tissue; ECM: Extracellular matrix; EGFR: Epidermal growth factor receptor; FFA: Free fatty acids; GF: Germ-free; HA: Hyaluronan; HAS: Hyaluronan synthase; HGF: Hepatocyte growth factor; HIF: Hypoxia inducible factor; HRE: Hormone response element; IFP: Interstitial fluid pressure;

IL: Interleukin; KC: Kras ${ }^{\mathrm{G} 12 \mathrm{D} /{ }^{+}}$; Ptfla ${ }^{\mathrm{Cre}}$; KPC: Kras ${ }^{\mathrm{G12D} /+} \operatorname{Trp} 53^{\mathrm{R} 172 \mathrm{H+}+}$; KRAS: Kirsten rat sarcoma viral oncogene homolog; OBR: Leptin receptor; LPS: Lipopolysaccharide; MMPs: Matrix metalloproteinases; PAG: PEGPH20 + nab-paclitaxel/gemcitabine; Panln: Pancreatic intra-epithelial neoplasia lesions; PC: Pancreatic cancer; PCDM: PC-associated diabetes mellitus; PDAC: Pancreatic ductal adenocarcinoma; PEGPH20: Pegylated recombinant human hyaluronidase; PFS: Progression-free survival; PSC: Pancreatic stellate cells; T2DM: Type 2 diabetes mellitus; TE: Thromboembolic event rate; TG: Triglycerides; TLR: Toll like receptor; TNF: Tumor necrotic factor; VNN: Vannin; WT: Wild-type
\end{abstract}

Acknowledgment

We thank Dr. Jessica Mercer for her editorial contributions.

\section{Funding}

The authors on this manuscript were supported, in part, by grants from the $\mathrm{NIH}$ [RO1 CA210637, RO1CA206444, and RO1 CA183459, UO1 CA200466, P50 CA127297 and PO1 CA217798].

\section{Availability of data and materials}

Not applicable

\section{Authors' contributions}

RP, SR and SKB planned the manuscript. SR, WMJ, SC, SV, SK and SKB revised and corrected the manuscript. All authors read and approved the final manuscript.

\section{Ethics approval and consent to participate} Not applicable

\section{Consent for publication}

All authors read and approved the final manuscript.

\section{Competing interests}

SKB is one of the co-founders of Sanguine Diagnostics and Therapeutics, Inc. WMJ is Chief Scientific Officer of Sanguine Diagnostics and Therapeutics, Inc. Other authors declare no competing interests. 


\section{Publisher's Note}

Springer Nature remains neutral with regard to jurisdictional claims in published maps and institutional affiliations.

\section{Author details \\ 'Department of Biochemistry and Molecular Biology, University of Nebraska Medical Center, Omaha, NE, USA. ${ }^{2}$ Sanguine Diagnostics and Therapeutics, University of Nebraska Medical Center, Omaha, NE, USA. ${ }^{3}$ Department of Cellular \& Integrative Physiology, University of Nebraska Medical Center, Omaha, NE, USA. ${ }^{4}$ Fred \& Pamela Buffet Cancer Center, University of Nebraska Medical Center, Omaha, NE, USA. ${ }^{5}$ Eppley Institute for Research in Cancer and Allied Diseases, University of Nebraska Medical Center, Omaha, NE, USA.}

\section{Received: 28 August 2018 Accepted: 14 November 2018} Published online: 19 December 2018

\section{References}

1. Majumder S, Chari ST, Ahlquist DA. Molecular detection of pancreatic neoplasia: Current status and future promise. World J Gastroenterol. 2015; 21(40):11387-95.

2. Siegel RL, Miller KD, Jemal A. Cancer statistics, 2018. CA Cancer J Clin. 2018; 68(1):7-30.

3. Hall BR, Cannon A, Atri P, Wichman CS, Smith LM, Ganti AK, et al. Advanced pancreatic cancer: a meta-analysis of clinical trials over thirty years. Oncotarget. 2018:9(27):19396-405.

4. Hidalgo M. Pancreatic cancer. N Engl J Med. 2010;362(17):1605-17.

5. Chari ST. Detecting early pancreatic cancer: problems and prospects. Semin Oncol. 2007;34(4):284-94.

6. Conlon KC, Klimstra DS, Brennan MF. Long-term survival after curative resection for pancreatic ductal adenocarcinoma. Clinicopathologic analysis of 5-year survivors. Ann Surg. 1996;223(3):273-9.

7. Chakraborty S, Baine MJ, Sasson AR, Batra SK. Current status of molecula markers for early detection of sporadic pancreatic cancer. Biochim Biophys Acta. 2011:1815(1):44-64

8. Momi N, Kaur S, Ponnusamy MP, Kumar S, Wittel UA, Batra SK. Interplay between smoking-induced genotoxicity and altered signaling in pancreatic carcinogenesis. Carcinogenesis. 2012;33(9):1617-28.

9. Chu GC, Kimmelman AC, Hezel AF, DePinho RA. Stromal biology of pancreatic cancer. J Cell Biochem. 2007;101(4):887-907.

10. Erkan M, Reiser-Erkan C, Michalski CW, Deucker S, Sauliunaite D, Streit S, et al. Cancer-stellate cell interactions perpetuate the hypoxia-fibrosis cycle in pancreatic ductal adenocarcinoma. Neoplasia. 2009;11(5):497-508.

11. Mahadevan D, Von Hoff DD. Tumor-stroma interactions in pancreatic ductal adenocarcinoma. Mol Cancer Ther. 2007;6(4):1186-97.

12. Masamune A, Shimosegawa T. Signal transduction in pancreatic stellate cells. J Gastroenterol. 2009;44(4):249-60.

13. Cannon A, Thompson C, Hall BR, Jain M, Kumar S, Batra SK. Desmoplasia in pancreatic ductal adenocarcinoma: insight into pathological function and therapeutic potential. Genes Cancer. 2018:9(3-4):78-86.

14. Feldmann $\mathrm{G}$, Beaty $\mathrm{R}$, Hruban $\mathrm{RH}$, Maitra A. Molecular genetics of pancreatic intraepithelial neoplasia. J Hepatobiliary Pancreat Surg. 2007;14(3):224-32.

15. Guo J, Xie K, Zheng S. Molecular biomarkers of pancreatic intraepithelial neoplasia and their implications in early diagnosis and therapeutic intervention of pancreatic cancer. Int J Biol Sci. 2016:12(3):292-301.

16. Qin R, Smyrk TC, Reed NR, Schmidt RL, Schnelldorfer T, Chari ST, et al. Combining clinicopathological predictors and molecular biomarkers in the oncogenic K-RAS/Ki67/HIF-1alpha pathway to predict survival in resectable pancreatic cancer. Br J Cancer. 2015:112(3):514-22.

17. Kaur S, Baine MJ, Jain M, Sasson AR, Batra SK. Early diagnosis of pancreatic cancer: challenges and new developments. Biomark Med. 2012:6(5):597-612.

18. Kaur S, Smith LM, Patel A, Menning M, Watley DC, Malik SS, et al. A combination of muc5ac and CA19-9 improves the diagnosis of pancreatic cancer: a multicenter study. Am J Gastroenterol. 2017;112(1):172-83.

19. Nix GA, Schmitz PI, Wilson JH, Van BM, Groeneveld CF, Hofwijk R. Carcinoma of the head of the pancreas. Therapeutic implications of endoscopic retrograde cholangiopancreatography findings. Gastroenterology. 1984; 87(1):37-43

20. Yachida S, Jones S, Bozic I, Antal T, Leary R, Fu B, et al. Distant metastasis occurs late during the genetic evolution of pancreatic cancer. Nature. 2010; 467(7319):1114-7.
21. Kaur S, Kumar S, Momi N, Sasson AR, Batra SK. Mucins in pancreatic cancer and its microenvironment. Nat Rev Gastroenterol Hepatol. 2013; 10(10):607-20.

22. Childs EJ, Mocci E, Campa D, Bracci PM, Gallinger S, Goggins M, et al. Common variation at 2p13.3, 3q29, 7p13 and 17q25.1 associated with susceptibility to pancreatic cancer. Nat Genet. 2015;47(8):911-6.

23. Herreros-Villanueva M, Bujanda L. Glypican-1 in exosomes as biomarker for early detection of pancreatic cancer. Ann Transl Med. 2016:4(4):64.

24. Moore MJ, Goldstein D, Hamm J, Figer A, Hecht JR, Gallinger S, et al. Erlotinib plus gemcitabine compared with gemcitabine alone in patients with advanced pancreatic cancer: a phase III trial of the National Cancer Institute of Canada Clinical Trials Group. J Clin Oncol. 2007;25(15):1960-6.

25. Conroy T, Desseigne F, Ychou M, Bouche O, Guimbaud R, Becouarn Y, et al. FOLFIRINOX versus gemcitabine for metastatic pancreatic cancer. N Engl J Med. 2011;364(19):1817-25.

26. Goldstein D, El-Maraghi RH, Hammel P, Heinemann V, Kunzmann V, Sastre J, et al. Nab-paclitaxel plus gemcitabine for metastatic pancreatic cancer: long-term survival from a phase III trial. J Natl Cancer Inst. 2015;107(2): dju413. https://doi.org/10.1093/jnci/dju413.

27. Von Hoff DD, Ervin T, Arena FP, Chiorean EG, Infante J, Moore M, et al. Increased survival in pancreatic cancer with nab-paclitaxel plus gemcitabine. N Engl J Med. 2013;369(18):1691-703.

28. Loc WS, Smith JP, Matters G, Kester M, Adair JH. Novel strategies for managing pancreatic cancer. World J Gastroenterol. 2014;20(40):14717-25.

29. Liu H, Huang D, McArthur DL, Boros LG, Nissen N, Heaney AP. Fructose induces transketolase flux to promote pancreatic cancer growth. Cancer Res. 2010;70(15):6368-76.

30. Nadler ST, Attie AD. Please pass the chips: genomic insights into obesity and diabetes. J Nutr. 2001;131(8):2078-81.

31. Pothuraju R, Sharma RK, Chagalamarri J, Jangra S, Kumar KP. A systematic review of gymnema sylvestre in obesity and diabetes management. J Sci Food Agric. 2014:94(5):834-40.

32. Reaven G. Metabolic syndrome: pathophysiology and implications for management of cardiovascular disease. Circulation. 2002;106(3):286-8.

33. Gumbs AA. Obesity, pancreatitis, and pancreatic cancer. Obes Surg. 2008; 18(9):1183-7.

34. Michaud DS, Giovannucci E, Willett WC, Colditz GA, Stampfer MJ, Fuchs CS Physical activity, obesity, height, and the risk of pancreatic cancer. JAMA. 2001;286(8):921-9.

35. Hori M, Takahashi M, Hiraoka N, Yamaji T, Mutoh M, Ishigamori R, et al. Association of pancreatic Fatty infiltration with pancreatic ductal adenocarcinoma. Clin Transl Gastroenterol. 2014;5:e53.

36. Zyromski NJ, Mathur A, Pitt HA, Wade TE, Wang S, Nakshatri P, et al. Obesity potentiates the growth and dissemination of pancreatic cancer. Surgery. $2009 \cdot 146(2) \cdot 258-63$

37. Hefetz-Sela S, Scherer PE. Adipocytes: impact on tumor growth and potential sites for therapeutic intervention. Pharmacol Ther. 2013:138(2):197-210.

38. Smits MM, van Geenen EJ. The clinical significance of pancreatic steatosis. Nat Rev Gastroenterol Hepatol. 2011:8(3):169-77.

39. Berger NA. Obesity and cancer pathogenesis. Ann N Y Acad Sci. 2014;1311:57-76.

40. Renehan AG, Tyson M, Egger M, Heller RF, Zwahlen M. Body-mass index and incidence of cancer: a systematic review and meta-analysis of prospective observational studies. Lancet. 2008:371(9612):569-78.

41. Momi N, Kaur S, Krishn SR, Batra SK. Discovering the route from inflammation to pancreatic cancer. Minerva Gastroenterol Dietol. 2012;58(4):283-97.

42. Incio J, Liu H, Suboj P, Chin SM, Chen IX, Pinter M, et al. Obesity-induced inflammation and desmoplasia promote pancreatic cancer progression and resistance to chemotherapy. Cancer Discov. 2016;6(8):852-69.

43. Wormann SM, Algul H. Risk factors and therapeutic targets in pancreatic cancer. Front Oncol. 2013:3:282

44. Khandekar MJ, Cohen P, Spiegelman BM. Molecular mechanisms of cancer development in obesity. Nat Rev Cancer. 2011:11(12):886-95.

45. Hu E, Liang P, Spiegelman BM. AdipoQ is a novel adipose-specific gene dysregulated in obesity. J Biol Chem. 1996:271(18):10697-703.

46. Scherer PE, Williams S, Fogliano M, Baldini G, Lodish HF. A novel serum protein similar to C1q, produced exclusively in adipocytes. J Biol Chem. 1995;270(45):26746-9.

47. Wijesekara N, Krishnamurthy M, Bhattacharjee A, Suhail A, Sweeney G, Wheeler MB. Adiponectin-induced ERK and Akt phosphorylation protects against pancreatic beta cell apoptosis and increases insulin gene expression and secretion. J Biol Chem. 2010;285(44):33623-31. 
48. Huang B, Cheng X, Wang D, Peng $M$, Xue Z, Da Y, et al. Adiponectin promotes pancreatic cancer progression by inhibiting apoptosis via the activation of AMPK/Sirt1/PGC-1alpha signaling. Oncotarget. 2014;5(13): 4732-45.

49. Kadri Colakoglu M, Bostanci EB, Ozdemir Y, Dalgic T, Aksoy E, Ozer I, et al. Roles of adiponectin and leptin as diagnostic markers in pancreatic cancer Bratisl Lek Listy. 2017;118(7):394-8.

50. Pezzilli R, Barassi A, Corsi MM, Morselli-Labate AM, Campana D, Casadei R, et al. Serum leptin, but not adiponectin and receptor for advanced glycation end products, is able to distinguish autoimmune pancreatitis from both chronic pancreatitis and pancreatic neoplasms. Scand J Gastroenterol. 2010;45(1):93-9.

51. Bao Y, Giovannucci EL, Kraft P, Stampfer MJ, Ogino S, Ma J, et al. A prospective study of plasma adiponectin and pancreatic cancer risk in five US cohorts. J Natl Cancer Inst. 2013;105(2):95-103.

52. Grote VA, Rohrmann S, Dossus L, Nieters A, Halkjaer J, Tjonneland A, et al. The association of circulating adiponectin levels with pancreatic cancer risk: a study within the prospective EPIC cohort. Int J Cancer. 2012;130(10):2428-37.

53. Kuruma S, Egawa N, Kurata M, Honda G, Kamisawa T, Ueda J, et al. Casecontrol study of diabetes-related genetic variants and pancreatic cancer risk in Japan. World J Gastroenterol. 2014;20(46):17456-62.

54. Yang JP, Li X, Wang F, Gao M, Li SL, Chen KS. Association analysis of genetic variants of adiponectin gene and risk of pancreatic cancer. Int J Clin Exp Med. 2015:8(5):8094-100.

55. Peters KE, Beilby J, Cadby G, Warrington NM, Bruce DG, Davis WA, et al. A comprehensive investigation of variants in genes encoding adiponectin (ADIPOQ) and its receptors (ADIPOR1/R2), and their association with serum adiponectin, type 2 diabetes, insulin resistance and the metabolic syndrome. BMC Med Genet. 2013;14:15.

56. Bub JD, Miyazaki T, Iwamoto Y. Adiponectin as a growth inhibitor in prostate cancer cells. Biochem Biophys Res Commun. 2006;340(4):1158-66.

57. Kim AY, Lee YS, Kim KH, Lee JH, Lee HK, Jang SH, et al. Adiponectin represses colon cancer cell proliferation via AdipoR1- and -R2-mediated AMPK activation. Mol Endocrinol. 2010;24(7):1441-52.

58. Bao B, Wang Z, Li Y, Kong D, Ali S, Banerjee $\mathrm{S}$, et al. The complexities of obesity and diabetes with the development and progression of pancreatic cancer. Biochim Biophys Acta. 2011;1815(2):135-46.

59. Vansaun MN. Molecular pathways: adiponectin and leptin signaling in cancer. Clin Cancer Res. 2013;19(8):1926-32.

60. Herreros-Villanueva M, Hijona E, Cosme A, Bujanda L. Mouse models of pancreatic cancer. World J Gastroenterol. 2012;18(12):1286-94.

61. Lanza-Jacoby S, Yan G, Radice G, LePhong C, Baliff J, Hess R. Calorie restriction delays the progression of lesions to pancreatic cancer in the LSL-KrasG12D; Pdx-1/Cre mouse model of pancreatic cancer. Exp Biol Med (Maywood ). 2013;238(7):787-97.

62. Kato M, Watabe K, Tsujii M, Funahashi T, Shimomura I, Takehara T. Adiponectin inhibits murine pancreatic cancer growth. Dig Dis Sci. 2014; 59(6):1192-6.

63. Messaggio F, Mendonsa AM, Castellanos J, Nagathihalli NS, Gorden L, Merchant NB, et al. Adiponectin receptor agonists inhibit leptin induced PSTAT3 and in vivo pancreatic tumor growth. Oncotarget. 2017;8(49):85378-91.

64. Tamori Y, Kasuga M. Glypican-4 is a new comer of adipokines working as insulin sensitizer. J Diabetes Investig. 2013;4(3):250-1.

65. Zhang Y, Guo KY, Diaz PA, Heo M, Leibel RL. Determinants of leptin gene expression in fat depots of lean mice. Am J Physiol Regul Integr Comp Physiol. 2002;282(1):R226-R34.

66. Ozcan L, Ergin AS, Lu A, Chung J, Sarkar S, Nie D, et al. Endoplasmic reticulum stress plays a central role in development of leptin resistance. Cell Metab. 2009;9(1):35-51.

67. Ren $H$, Jia L, Zhao T, Zhang H, Chen J, Yang S, et al. Hypoxia inducible factor (HIF)-1alpha directly activates leptin receptor (Ob-R) in pancreatic cancer cells. Cancer Lett. 2014;354(1):172-80.

68. Fan Y, Gan Y, Shen Y, Cai X, Song Y, Zhao F, et al. Leptin signaling enhances cell invasion and promotes the metastasis of human pancreatic cancer via increasing MMP-13 production. Oncotarget. 2015;6(18):16120-34.

69. Fujiwara Y, Kobayashi T, Chayahara N, Imamura Y, Toyoda M, Kiyota N, et al. Metabolomics evaluation of serum markers for cachexia and their intra-day variation in patients with advanced pancreatic cancer. PLoS One. 2014;9(11):e113259.
70. Harbuzariu A, Rampoldi A, Daley-Brown DS, Candelaria P, Harmon TL, Lipsey CC, et al. Leptin-notch signaling axis is involved in pancreatic cancer progression. Oncotarget. 2017;8(5):7740-52.

71. Harbuzariu A, Gonzalez-Perez RR. Leptin-notch axis impairs 5-fluorouracil effects on pancreatic cancer. Oncotarget. 2018;9(26):18239-53.

72. Arumugam M, Raes J, Pelletier E, Le PD, Yamada T, Mende DR, et al. Enterotypes of the human gut microbiome. Nature. 2011;473(7346): 174-80.

73. Mima K, Nakagawa S, Sawayama H, Ishimoto T, Imai K, Iwatsuki M, et al. The microbiome and hepatobiliary-pancreatic cancers. Cancer Lett. 2017:402:9-15.

74. Goyert SM, Ferrero E, Rettig WJ, Yenamandra AK, Obata F, Le Beau MM. The CD14 monocyte differentiation antigen maps to a region encoding growth factors and receptors. Science. 1988;239(4839):497-500.

75. Haziot A, Chen S, Ferrero E, Low MG, Silber R, Goyert SM. The monocyte differentiation antigen, CD14, is anchored to the cell membrane by a phosphatidylinositol linkage. J Immunol. 1988;141(2):547-52.

76. Cani PD, Bibiloni R, Knauf C, Waget A, Neyrinck AM, Delzenne NM, et al. Changes in gut microbiota control metabolic endotoxemia-induced inflammation in high-fat diet-induced obesity and diabetes in mice. Diabetes. 2008;57(6):1470-81.

77. Ehses JA, Perren A, Eppler E, Ribaux P, Pospisilik JA, Maor-Cahn R, et al. Increased number of islet-associated macrophages in type 2 diabetes. Diabetes. 2007;56(9):2356-70.

78. Varma V, Yao-Borengasser A, Rasouli N, Nolen GT, Phanavanh B, Starks T, et al. Muscle inflammatory response and insulin resistance: synergistic interaction between macrophages and fatty acids leads to impaired insulin action. Am J Physiol Endocrinol Metab. 2009;296(6):E1300-E10.

79. Coussens LM, Tinkle CL, Hanahan D, Werb Z. MMP-9 supplied by bone marrow-derived cells contributes to skin carcinogenesis. Cell. 2000; 103(3):481-90.

80. Murdoch C, Muthana M, Coffelt SB, Lewis CE. The role of myeloid cells in the promotion of tumour angiogenesis. Nat Rev Cancer. 2008;8(8):618-31.

81. Pollard JW. Tumour-educated macrophages promote tumour progression and metastasis. Nat Rev Cancer. 2004:4(1):71-8.

82. Zambirinis CP, Pushalkar S, Saxena D, Miller G. Pancreatic cancer, inflammation, and microbiome. Cancer J. 2014;20(3):195-202.

83. Li Y, Kundu P, Seow SW, de Matos CT, Aronsson L, Chin KC, et al. Gut microbiota accelerate tumor growth via c-jun and STAT3 phosphorylation in APCMin/+ mice. Carcinogenesis. 2012;33(6):1231-8.

84. Uronis JM, Muhlbauer M, Herfarth HH, Rubinas TC, Jones GS, Jobin C. Modulation of the intestinal microbiota alters colitis-associated colorectal cancer susceptibility. PLoS One. 2009;4(6):e6026.

85. Tsuji Y, Watanabe T, Kudo M, Arai H, Strober W, Chiba T. Sensing of commensal organisms by the intracellular sensor NOD1 mediates experimental pancreatitis. Immunity. 2012;37(2):326-38.

86. Frulloni L, Lunardi C, Simone R, Dolcino M, Scattolini C, Falconi M, et al. Identification of a novel antibody associated with autoimmune pancreatitis. N Engl J Med. 2009;361(22):2135-42.

87. Leal-Lopes C, Velloso FJ, Campopiano JC, Sogayar MC, Correa RG. Roles of commensal microbiota in pancreas homeostasis and pancreatic pathologies. J Diabetes Res. 2015;2015:284680.

88. Sethi V, Kurtom S, Tarique M, Lavania S, Malchiodi Z, Hellmund L, et al. Gut microbiota promotes tumor growth in mice by modulating immune response. Gastroenterology. 2018;155(1):33-7 e6.

89. Nofrarias M, Martinez-Puig D, Pujols J, Majo N, Perez JF. Long-term intake of resistant starch improves colonic mucosal integrity and reduces gut apoptosis and blood immune cells. Nutrition. 2007;23(11-12):861-70.

90. Panebianco C, Adamberg K, Adamberg S, Saracino C, Jaagura M, Kolk K, et al. Engineered resistant-starch (ers) diet shapes colon microbiota profile in parallel with the retardation of tumor growth in in vitro and in vivo pancreatic cancer models. Nutrients. 2017;9(4):331.

91. Panebianco C, Adamberg K, Jaagura M, Copetti M, Fontana A Adamberg $S$, et al. Influence of gemcitabine chemotherapy on the microbiota of pancreatic cancer xenografted mice. Cancer Chemother Pharmacol. 2018;81(4):773-82.

92. Pushalkar S, Hundeyin M, Daley D, Zambirinis CP, Kurz E, Mishra A, et al. The pancreatic cancer microbiome promotes oncogenesis by induction of innate and adaptive immune suppression. Cancer Discov. 2018;8(4):403-16.

93. Hotamisligil GS, Arner P, Caro JF, Atkinson RL, Spiegelman BM. Increased adipose tissue expression of tumor necrosis factor-alpha in human obesity and insulin resistance. J Clin Invest. 1995;95(5):2409-15. 
94. Hotamisligil GS, Shargill NS, Spiegelman BM. Adipose expression of tumor necrosis factor-alpha: direct role in obesity-linked insulin resistance. Science. 1993;259(5091):87-91.

95. Orosz P, Echtenacher B, Falk W, Ruschoff J, Weber D, Mannel DN. Enhancement of experimental metastasis by tumor necrosis factor. J Exp Med. 1993;177(5):1391-8

96. Bredel M, Scholtens DM, Yadav AK, Alvarez AA, Renfrow JJ, Chandler JP, et al. NFKBIA deletion in glioblastomas. N Engl J Med. 2011;364(7):627-37.

97. Calado DP, Zhang B, Srinivasan L, Sasaki Y, Seagal J, Unitt C, et al. Constitutive canonical NF-kappaB activation cooperates with disruption of BLIMP1 in the pathogenesis of activated B cell-like diffuse large cell lymphoma. Cancer Cell. 2010;18(6):580-9.

98. Wang W, Abbruzzese JL, Evans DB, Larry L, Cleary KR, Chiao PJ. The nuclear factor-kappa B RelA transcription factor is constitutively activated in human pancreatic adenocarcinoma cells. Clin Cancer Res. 1999;5(1):119-27.

99. De ML, Reni M, Tassi E, Clavenna D, Papa I, Recalde H, et al. Intratumor T helper type 2 cell infiltrate correlates with cancer-associated fibroblast thymic stromal lymphopoietin production and reduced survival in pancreatic cancer. J Exp Med. 2011;208(3):469-78.

100. Demols A, Le MO, Desalle F, Quertinmont E, Van Laethem JL, Deviere J. CD4(+ )T cells play an important role in acute experimental pancreatitis in mice. Gastroenterology. 2000;118(3):582-90.

101. Bromberg JF, Wrzeszczynska MH, Devgan G, Zhao Y, Pestell RG, Albanese C, et al. Stat3 as an oncogene. Cell. 1999;98(3):295-303.

102. Fukuda A, Wang SC, Morris JP, Folias AE, Liou A, Kim GE, et al. Stat3 and MMP7 contribute to pancreatic ductal adenocarcinoma initiation and progression. Cancer Cell. 2011;19(4):441-55.

103. Lesina M, Kurkowski MU, Ludes K, Rose-John S, Treiber M, Kloppel G, et al. Stat3/Socs3 activation by IL-6 transsignaling promotes progression of pancreatic intraepithelial neoplasia and development of pancreatic cancer. Cancer Cell. 2011;19(4):456-69.

104. Yu H, Pardoll D, Jove R. STATs in cancer inflammation and immunity: a leading role for STAT3. Nat Rev Cancer. 2009;9(11):798-809.

105. Akakura N, Kobayashi M, Horiuchi I, Suzuki A, Wang J, Chen J, et al. Constitutive expression of hypoxia-inducible factor-1alpha renders pancreatic cancer cells resistant to apoptosis induced by hypoxia and nutrient deprivation. Cancer Res. 2001;61(17):6548-54.

106. Iqbal MA, Gupta V, Gopinath P, Mazurek S, Bamezai RN. Pyruvate kinase M2 and cancer: an updated assessment. FEBS Lett. 2014;588(16):2685-92.

107. Wang HJ, Hsieh YJ, Cheng WC, Lin CP, Lin YS, Yang SF, et al. JMJD5 regulates PKM2 nuclear translocation and reprograms HIF-1alpha-mediated glucose metabolism. Proc Natl Acad Sci U S A. 2014;111(1):279-84.

108. Wong N, Ojo D, Yan J, Tang D. PKM2 contributes to cancer metabolism. Cancer Lett. 2015;356(2 Pt A):184-91.

109. Mohammad GH, Olde Damink SW, Malago M, Dhar DK, Pereira SP. Pyruvate kinase $\mathrm{m} 2$ and lactate dehydrogenase a are overexpressed in pancreatic cancer and correlate with poor outcome. PLoS One. 2016;11(3):e0151635.

110. Li Z, Yang P, Li Z. The multifaceted regulation and functions of PKM2 in tumor progression. Biochim Biophys Acta. 2014;1846(2):285-96.

111. Yang W, Xia Y, Ji H, Zheng Y, Liang J, Huang W, et al. Nuclear PKM2 regulates beta-catenin transactivation upon EGFR activation. Nature. 2011; 480(7375):118-22.

112. Vonlaufen A, Joshi S, Qu C, Phillips PA, Xu Z, Parker NR, et al. Pancreatic stellate cells: partners in crime with pancreatic cancer cells. Cancer Res. 2008;68(7):2085-93.

113. Vonlaufen A, Phillips PA, Xu Z, Goldstein D, Pirola RC, Wilson JS, et al. Pancreatic stellate cells and pancreatic cancer cells: an unholy alliance. Cancer Res. 2008;68(19):7707-10.

114. Bell LN, Cai L, Johnstone BH, Traktuev DO, March KL, Considine RV. A central role for hepatocyte growth factor in adipose tissue angiogenesis. Am J Physiol Endocrinol Metab. 2008;294(2):E336-E44.

115. Jiang WG, Martin TA, Parr C, Davies G, Matsumoto K, Nakamura T. Hepatocyte growth factor, its receptor, and their potential value in cancer therapies. Crit Rev Oncol Hematol. 2005;53(1):35-69.

116. Bell LN, Ward JL, Degawa-Yamauchi M, Bovenkerk JE, Jones R, Cacucci $\mathrm{BM}$, et al. Adipose tissue production of hepatocyte growth factor contributes to elevated serum HGF in obesity. Am J Physiol Endocrinol Metab. 2006;291(4):E843-E8.

117. Ziegler KM, Considine RV, True E, Swartz-Basile DA, Pitt HA, Zyromski NJ. Adipocytes enhance murine pancreatic cancer growth via a hepatocyte growth factor (HGF)-mediated mechanism. Int J Surg. 2016;28:179-84.
118. Pothula SP, Xu Z, Goldstein D, Biankin AV, Pirola RC, Wilson JS, et al. Hepatocyte growth factor inhibition: a novel therapeutic approach in pancreatic cancer. Br J Cancer. 2016;114(3):269-80.

119. Logan-Collins J, Thomas RM, Yu P, Jaquish D, Mose E, French R, et al. Silencing of RON receptor signaling promotes apoptosis and gemcitabine sensitivity in pancreatic cancers. Cancer Res. 2010;70(3):1130-40.

120. Cui J, Xia T, Xie D, Gao Y, Jia Z, Wei D, et al. HGF/Met and FOXM1 form a positive feedback loop and render pancreatic cancer cells resistance to Met inhibition and aggressive phenotypes. Oncogene. 2016;35(36):4708-18.

121. Birchmeier C, Birchmeier W, Gherardi E, Vande Woude GF. Met, metastasis, motility and more. Nat Rev Mol Cell Biol. 2003;4(12):915-25.

122. Wong KM, Horton KJ, Coveler AL, Hingorani SR, Harris WP. Targeting the tumor stroma: the biology and clinical development of pegylated recombinant human hyaluronidase (PEGPH20). Curr Oncol Rep. 2017; 19(7):47.

123. Chajara A, Raoudi M, Delpech B, Leroy M, Basuyau JP, Levesque H. Increased hyaluronan and hyaluronidase production and hyaluronan degradation in injured aorta of insulin-resistant rats. Arterioscler Thromb Vasc Biol. 2000; 20(6):1480-7.

124. Weiss L, Slavin S, Reich S, Cohen P, Shuster S, Stern R, et al. Induction of resistance to diabetes in non-obese diabetic mice by targeting CD44 with a specific monoclonal antibody. Proc Natl Acad Sci U S A. 2000;97(1):285-90.

125. Kang L, Lantier L, Kennedy A, Bonner JS, Mayes WH, Bracy DP, et al. Hyaluronan accumulates with high-fat feeding and contributes to insulin resistance. Diabetes. 2013;62(6):1888-96.

126. Sato N, Cheng XB, Kohi S, Koga A, Hirata K. Targeting hyaluronan for the treatment of pancreatic ductal adenocarcinoma. Acta Pharm Sin B. 2016; 6(2):101-5.

127. Itano N, Zhuo L, Kimata K. Impact of the hyaluronan-rich tumor microenvironment on cancer initiation and progression. Cancer Sci. 2008; 99(9):1720-5.

128. Sato N, Kohi S, Hirata K, Goggins M. Role of hyaluronan in pancreatic cancer biology and therapy: Once again in the spotlight. Cancer Sci. 2016;107(5): 569-75.

129. Sironen RK, Tammi M, Tammi R, Auvinen PK, Anttila M, Kosma VM. Hyaluronan in human malignancies. Exp Cell Res. 2011;317(4):383-91.

130. Cheng XB, Sato N, Kohi S, Koga A, Hirata K. Receptor for hyaluronic acid-mediated motility is associated with poor survival in pancreatic ductal adenocarcinoma. J Cancer. 2015;6(11):1093-8.

131. Immervoll $H$, Hoem D, Steffensen OJ, Miletic $H$, Molven A. Visualization of CD44 and CD133 in normal pancreas and pancreatic ductal adenocarcinomas: non-overlapping membrane expression in cell populations positive for both markers. J Histochem Cytochem. 2011;59(4):441-55.

132. Misra S, Hascall VC, Markwald RR, Ghatak S. Interactions between hyaluronan and Its receptors (CD44, RHAMM) regulate the activities of inflammation and cancer. Front Immunol. 2015;6:201

133. Theocharis AD, Tsara ME, Papageorgacopoulou N, Karavias DD, Theocharis DA. Pancreatic carcinoma is characterized by elevated content of hyaluronan and chondroitin sulfate with altered disaccharide composition. Biochim Biophys Acta. 2000;1502(2):201-6.

134. Kohi S, Sato N, Cheng XB, Koga A, Higure A, Hirata K. A novel epigenetic mechanism regulating hyaluronan production in pancreatic cancer cells. Clin Exp Metastasis. 2016:33(3):225-30.

135. Cheng XB, Kohi S, Koga A, Hirata K, Sato N. Hyaluronan stimulates pancreatic cancer cell motility. Oncotarget. 2016;7(4):4829-40.

136. Polvani S, Tarocchi M, Tempesti S, Bencini L, Galli A. Peroxisome proliferator activated receptors at the crossroad of obesity, diabetes, and pancreatic cancer. World J Gastroenterol. 2016;22(8):2441-59.

137. Provenzano PP, Cuevas C, Chang AE, Goel VK, Von Hoff DD, Hingorani SR. Enzymatic targeting of the stroma ablates physical barriers to treatment of pancreatic ductal adenocarcinoma. Cancer Cell. 2012;21(3):418-29.

138. Hingorani SR, Zheng L, Bullock AJ, Seery TE, Harris WP, Sigal DS, et al. HALO 202: randomized phase II study of PEGPH20 plus nab-paclitaxel/gemcitabine versus nab-paclitaxel/gemcitabine in patients with untreated, metastatic pancreatic ductal adenocarcinoma. J Clin Oncol. 2018;36(4):359-66.

139. Gallagher EJ, LeRoith D. Obesity and diabetes: the increased risk of cancer and cancer-related mortality. Physiol Rev. 2015;95(3):727-48.

140. Andersen DK. Diabetes and cancer: placing the association in perspective. Curr Opin Endocrinol Diabetes Obes. 2013;20(2):81-6.

141. Setiawan WW, Stram DO, Porcel J, Chari ST, Maskarinec G, Le Marchand L, et al. Pancreatic cancer following incident diabetes in african americans and 
latinos: the multiethnic cohort. J Natl Cancer Inst. 2019;111(1):djy090. https://doi.org/10.1093/jnci/djy090.

142. Grote VA, Becker S, Kaaks R. Diabetes mellitus type 2 - an independent risk factor for cancer? Exp Clin Endocrinol Diabetes. 2010;118(1):4-8.

143. Mayer D, Shukla A, Enzmann H. Proliferative effects of insulin analogues on mammary epithelial cells. Arch Physiol Biochem. 2008;114(1):38-44.

144. Li D, Yeung SC, Hassan MM, Konopleva M, Abbruzzese JL. Antidiabetic therapies affect risk of pancreatic cancer. Gastroenterology. 2009;137(2):482-8.

145. Huxley R, Ansary-Moghaddam A, de GA B, Barzi F, Woodward M. Type-II diabetes and pancreatic cancer: a meta-analysis of 36 studies. Br J Cancer. 2005;92(11):2076-83.

146. Chari ST, Leibson CL, Rabe KG, Ransom J, de Andrade M, Petersen GM. Probability of pancreatic cancer following diabetes: a population-based study. Gastroenterology. 2005;129(2):504-11.

147. Ogawa Y, Tanaka M, Inoue K, Yamaguchi K, Chijiiwa K, Mizumoto K, et al. A prospective pancreatographic study of the prevalence of pancreatic carcinoma in patients with diabetes mellitus. Cancer. 2002; 94(9):2344-9.

148. Gupta D, Krueger CB, Lastra G. Over-nutrition, obesity and insulin resistance in the development of beta-cell dysfunction. Curr Diabetes Rev. 2012;8(2):76-83.

149. Kahn SE, Hull RL, Utzschneider KM. Mechanisms linking obesity to insulin resistance and type 2 diabetes. Nature. 2006;444(7121):840-6.

150. Wang F, Herrington M, Larsson J, Permert J. The relationship between diabetes and pancreatic cancer. Mol Cancer. 2003;2:4

151. Hart PA, Baichoo E, Bi Y, Hinton A, Kudva YC, Chari ST. Pancreatic polypeptide response to a mixed meal is blunted in pancreatic head cancer associated with diabetes mellitus. Pancreatology. 2015;15(2):162-6.

152. Aggarwal G, Ramachandran V, Javeed N, Arumugam T, Dutta S, Klee GG, et al. Adrenomedullin is up-regulated in patients with pancreatic cancer and causes insulin resistance in beta cells and mice. Gastroenterology. 2012; 143(6):1510-7.

153. Senna AA, Zedan M, el-Salam GE, el-Mashad Al. Study of plasma adrenomedullin level in normal pregnancy and preclampsia. Medscape J Med. 2008;10(2):29.

154. Ramachandran V, Arumugam T, Hwang RF, Greenson JK, Simeone DM, Logsdon CD. Adrenomedullin is expressed in pancreatic cancer and stimulates cell proliferation and invasion in an autocrine manner via the adrenomedullin receptor. ADMR. Cancer Res. 2007;67(6):2666-75.

155. Ramachandran V, Arumugam T, Langley R, Hwang RF, Vivas-Mejia P, Sood AK, et al. The ADMR receptor mediates the effects of adrenomedullin on pancreatic cancer cells and on cells of the tumor microenvironment. PLoS One. 2009;4(10):e7502.

156. Natsuizaka M, Ozasa M, Darmanin S, Miyamoto M, Kondo S, Kamada S, et al. Synergistic up-regulation of Hexokinase-2, glucose transporters and angiogenic factors in pancreatic cancer cells by glucose deprivation and hypoxia. Exp Cell Res. 2007;313(15):3337-48.

157. Melo SA, Luecke LB, Kahlert C, Fernandez AF, Gammon ST, Kaye J, et al. Glypican-1 identifies cancer exosomes and detects early pancreatic cancer. Nature. 2015;523(7559):177-82.

158. AS EL, Mager I, Breakefield XO, Wood MJ. Extracellular vesicles: biology and emerging therapeutic opportunities. Nat Rev Drug Discov. 2013; 12(5):347-57.

159. Mathivanan S, Ji H, Simpson RJ. Exosomes: extracellular organelles important in intercellular communication. J Proteomics. 2010;73(10): 1907-20.

160. Shifrin DA Jr, Demory BM, Coffey RJ, Tyska MJ. Extracellular vesicles: communication, coercion, and conditioning. Mol Biol Cell. 2013;24(9): 1253-9.

161. Costa-Silva B, Aiello NM, Ocean AJ, Singh S, Zhang H, Thakur BK, et al. Pancreatic cancer exosomes initiate pre-metastatic niche formation in the liver. Nat Cell Biol. 2015;17(6):816-26.

162. Hoshino A, Costa-Silva B, Shen TL, Rodrigues G, Hashimoto A, Tesic MM, et al. Tumour exosome integrins determine organotropic metastasis. Nature. 2015;527(7578):329-35.

163. Javeed N, Sagar G, Dutta SK, Smyrk TC, Lau JS, Bhattacharya S, et al. Pancreatic cancer-derived exosomes cause paraneoplastic beta-cell dysfunction. Clin Cancer Res. 2015;21(7):1722-33.

164. Sagar G, Sah RP, Javeed N, Dutta SK, Smyrk TC, Lau JS, et al. Pathogenesis of pancreatic cancer exosome-induced lipolysis in adipose tissue. Gut. 2016; 65(7):1165-74
165. Hollander LL, Guo X, Salem RR, Cha CH. The novel tumor angiogenic factor, adrenomedullin-2, predicts survival in pancreatic adenocarcinoma. J Surg Res. 2015;197(2):219-24.

166. Maras B, Barra D, Dupre S, Pitari G. Is pantetheinase the actual identity of mouse and human vanin-1 proteins? FEBS Lett. 1999;461(3):149-52.

167. Pitari G, Malergue F, Martin F, Philippe JM, Massucci MT, Chabret C, et al. Pantetheinase activity of membrane-bound vanin-1: lack of free cysteamine in tissues of vanin-1 deficient mice. FEBS Lett. 2000;483(2-3):149-54.

168. Dupre S, Graziani MT, Rosei MA, Fabi A, Del GE. The enzymatic breakdown of pantethine to pantothenic acid and cystamine. Eur J Biochem. 1970;16(3):571-8.

169. van Diepen JA, Jansen PA, Ballak DB, Hijmans A, Rutjes FP, Tack CJ, et al. Genetic and pharmacological inhibition of vanin-1 activity in animal models of type 2 diabetes. Sci Rep. 2016;6:21906.

170. Huang H, Dong X, Kang MX, Xu B, Chen Y, Zhang B, et al. Novel blood biomarkers of pancreatic cancer-associated diabetes mellitus identified by peripheral blood-based gene expression profiles. Am J Gastroenterol. 2010; 105(7):1661-9.

171. Roisin-Bouffay C, Castellano R, Valero R, Chasson L, Galland F, Naquet P. Mouse vanin-1 is cytoprotective for islet beta cells and regulates the development of type 1 diabetes. Diabetologia. 2008;51(7):1192-201.

172. Berruyer C, Martin FM, Castellano R, Macone A, Malergue F, Garrido-Urbani $\mathrm{S}$, et al. Vanin-1-/- mice exhibit a glutathione-mediated tissue resistance to oxidative stress. Mol Cell Biol. 2004;24(16):7214-24.

173. Martin F, Penet MF, Malergue F, Lepidi H, Dessein A, Galland F, et al. Vanin-1(-/-) mice show decreased N. J Clin Invest. 2004;113(4):591-7.

174. Kang M, Qin W, Buya M, Dong X, Zheng W, Lu W, et al. VNN1, a potential biomarker for pancreatic cancer-associated new-onset diabetes, aggravates paraneoplastic islet dysfunction by increasing oxidative stress. Cancer Lett. 2016;373(2):241-50.

175. Williams JA. Regulation of normal and adaptive pancreatic growth. Pancreapedia: The Exocrine Pancreas Knowledge Base; 2017.

176. Matsuda A, Makino N, Tozawa T, Shirahata N, Honda T, Ikeda Y, et al. Pancreatic fat accumulation, fibrosis, and acinar cell injury in the Zucker diabetic fatty rat fed a chronic high-fat diet. Pancreas. 2014; 43(5):735-43.

177. Dawson DW, Hertzer K, Moro A, Donald G, Chang HH, Go VL, et al. High-fat, high-calorie diet promotes early pancreatic neoplasia in the conditional KrasG12D mouse model. Cancer Prev Res (Phila). 2013; 6(10):1064-73.

178. Yang J, Waldron RT, Su HY, Moro A, Chang HH, Eibl G, et al. Insulin promotes proliferation and fibrosing responses in activated pancreatic stellate cells. Am J Physiol Gastrointest Liver Physiol. 2016;311(4): G675-G87.

179. Butler AE, Galasso R, Matveyenko A, Rizza RA, Dry S, Butler PC. Pancreatic duct replication is increased with obesity and type 2 diabetes in humans. Diabetologia. 2010;53(1):21-6.

180. Nimmakayala RK, Seshacharyulu P, Lakshmanan I, Rachagani S, Chugh S, Karmakar S, et al. Cigarette smoke induces stem cell features of pancreatic cancer cells via PAF1. Gastroenterology. 2018;155(3):892-908.

181. Vaz AP, Deb S, Rachagani S, Dey P, Muniyan S, Lakshmanan I, et al. Overexpression of PD2 leads to increased tumorigenicity and metastasis in pancreatic ductal adenocarcinoma. Oncotarget. 2016; 7(3):3317-31.

182. Vaz AP, Ponnusamy MP, Batra SK. Cancer stem cells and therapeutic targets: an emerging field for cancer treatment. Drug Deliv Transl Res. 2013;3(2):113-20.

183. Mimeault M, Batra SK. Recent progress on normal and malignant pancreatic stem/progenitor cell research: therapeutic implications for the treatment of type 1 or 2 diabetes mellitus and aggressive pancreatic cancer. Gut. 2008; 57(10):1456-68

184. Tchio Mantho Cl, Harbuzariu A, Gonzalez-Perez RR. Histone deacetylases, microRNA and leptin crosstalk in pancreatic cancer. World J Clin Oncol. 2017:8(3):178-89.

185. Lipsey CC, Harbuzariu A, Daley-Brown D, Gonzalez-Perez RR. Oncogenic role of leptin and Notch interleukin-1 leptin crosstalk outcome in cancer. World J Methodol. 2016;6(1):43-55.

186. Rahn S, Zimmermann V, Viol F, Knaack H, Stemmer K, Peters L, et al. Diabetes as risk factor for pancreatic cancer: Hyperglycemia promotes epithelial-mesenchymal-transition and stem cell properties in pancreatic ductal epithelial cells. Cancer Lett. 2018;415:129-50. 